\title{
Study on Long-Term Exposure to Carbon Emissions and Lung Cancer Incidence Rate in China
}

\section{Fengdie He}

Chinese center for disease control and prevention

Yongqing Lin ( $\square$ yongqing0522@163.com )

Chinese Center for Disease Control and Prevention https://orcid.org/0000-0002-2563-1365

\section{Baohua Wang}

Chinese Center for Disease Control and Prevention

\section{Shaoxia Dong}

Chinese Center for Disease Control and Prevention

\section{Research Article}

Keywords: carbon emissions, lung cancer, long-term effect, spatial Durbin model (SDM)

Posted Date: September 22nd, 2021

DOI: https://doi.org/10.21203/rs.3.rs-860052/v1

License: (c) (i) This work is licensed under a Creative Commons Attribution 4.0 International License. Read Full License 


\section{Abstract}

Background: This study has shown the incidence of lung cancer in association with exposure to air pollution. We investigated the relationship, focusing on long-term exposure to carbon emissions (CE) and lung cancer incidence rate (LIR) in China.

Methods: We collected the incidence rate of lung cancer from 2013 to 2015, and the data of carbon emissions from 1997 to 2015. We modeled the panel data of 30 provinces and cities in China from 2013 to 2015 and applied a spatial Durbin model (SDM) to explore the spatial effect of CE on the LIR. Pearson test to determine the long-term impact of CE on LIR.

Findings: The results showed that the direct effect coefficient of CE and UR were 0.132 and 0.425 , respectively, both significant at a $1 \%$ level, which showed that CE and UR had an obvious positive effect on LIR. The value of Moran's I indicated that there was a positive spatial correlation between the LIR and CE in China from 2013 to 2015, while the indirect effect coefficient of all the variables was nonsignificant at a $10 \%$ level, which indicated that CE had not impact on the LIR of its surrounding areas. on the whole, the effect cofficient of $\mathrm{CE}$ is 0.005 , which is significant at a $1 \%$ level, which points out that the average effect of a change in CE in a certain region on LIR in all regions. Therefore, the research results indicated that there were geographical differences in carbon emissions but there is no spatial spillover effects. In the time fixed effects, the coefficients of CE were positive at the $10 \%$ significance level, which pointed out that CE exposure had a long-term impact on LIR from 2013 to 2015. Besides, the Pearson test implied that CE in the period had the greatest impact on the LIR in 2015 in China, and the lag period was about 17 years.

Interpretation: The impact of CE on LIR had geographical distribution differences and long-term effects in China. We recommend that adopting policies to reduce carbon emission will have a positive health impact.

\section{Highlights}

1. The results showed that the direct effect coefficients of the carbon emissions and urbanization rate were 0.132 and 0.425 , respectively, which showed that carbon emissions and urbanization rate had an obvious positive effect on lung cancer incidence rate.

2. We calculated the value of Moran's I and the indirect effect coefficient of all the variables and the results indicated that there were geographical differences in carbon emissions but no spatial spillover effects.

3. Carbon emission exposure had a long-term impact on lung cancer incidence rate from 2013 to 2015. In addition, Pearson test implied that carbon emission in the period had the greatest impact on the lung cancer incidence rate in 2015 in China, and the lag period was about 17 years.

\section{Introduction}

Carbon emission is a general term for greenhouse gas emissions, referring to the average greenhouse gas emissions from the production, transportation, use, and recycling of a product. When the organic hydrocarbons produced by fuel combustion come into complete contact with oxygen in the air, a chemical reaction of combustion will occur, and water and carbon dioxide $\left(\mathrm{CO}_{2}\right)$ will be produced. However, when combustion is incomplete, it may become harmful substances and be emitted, such as particulate matter (PM) and intermediate products carbon monoxide (CO). accounting for $71-76 \%$ of global carbon dioxide emissions generated by global energy use (Edenhofer et al. 2014). The latest statistics, published by the UK-based climate policy website Carbon Brief (https://www.carbonbrief.org/), showed that China's total carbon emissions reached 10 billion tons in 2018, up 2.3 percent from 2017. The rise in carbon emissions has increased air pollution and affected human health (Rafindadi et al. 2014). I In June 2020, the Ministry of Ecology and Environment of the People's Republic of China issued the "Announcement on China's Ecological Environment in 2019", which showed that in 2019, the average number of days of ambient air quality exceeding the standard in 337 cities nationwide was $18.0 \%$. The main pollutants of $\mathrm{PM}_{2.5}, \mathrm{O}_{3}, \mathrm{PM}_{10}, \mathrm{NO}_{2}$, and $\mathrm{CO}$ accounted for $45.0 \%, 41.7 \%$, $12.8 \%, 0.7 \%$, and less than $0.1 \%$ of the total number of excessive days. Moreover, according to the Global Burden of Disease (GBD) (Collaboration et al. 2020), particulate air pollution ranked fourth among the top ten risk factors affecting the number of deaths and the percentage of DALYs in China in 2017. 
Lung cancer ranks first among the top ten cancers in China in terms of morbidity and mortality, with a standardized incidence of $35.57 / 100,000$ and standardized mortality of $47.79 / 100,000$ (Song 2018). Recently, the research on the relationship between carbon emissions and lung cancer and other diseases has been increased. Lin et al. (Lin 2019) used Poisson regression to analyze the relationship between the LIR and carbon emissions in coal-fired power plants in Europe and Asia from 2000 to 2016 and found that the LIR was proportional to carbon emissions. Yue et al. (Shihong 2017) have studied the relationship between the LIR in 550 patients in 27 regions of Tianjin and various air pollutants and found that the combination of different air pollutants $\left(\mathrm{PM}_{2.5}, \mathrm{PM}_{10}\right.$, $\mathrm{SO}_{2}, \mathrm{NO}_{2}, \mathrm{CO}, \mathrm{O}_{3}$ ) and pollutants had different effects on the LIR in different regions of Tianjin. Besides, long-term epidemiological studies have reported an increased risk of all causes of mortality, cardiopulmonary mortality, and lung cancer mortality associated with increasing exposures to air pollution (Joellen 2007). A study in Egypt found that the number of deaths caused by air pollution (respiratory system and cardiovascular diseases) increased by $2.5 \%$ when carbon dioxide emissions increased by $1 \%$, and the impact of population growth on sustainable development opportunities depends on the degree to which increased air pollution leads to lower morbidity and thus lower labor productivity (Ghanem 2018).

In light of the above-mentioned concerns and based on panel data, the objectives of this study are: (1) to assess the relationship between carbon emissions and other economic indicators and lung cancer incidence rates in China; (2) to explore the effects of interregional carbon emissions on lung cancer incidence rate in local and adjacent areas; and (3) to identify the long-term impact of carbon emissions on lung cancer incidence rate. More specifically, the current study attempts to explore the temporal and spatial effects of carbon emissions on lung cancer incidence through panel data modeling and to explain the long-term effect of carbon emissions on lung cancer incidence rate.

\section{Data And Study Design}

\subsection{Data sources}

The incidence data of lung cancer (10th revision of the International Classification of Diseases code: ICD 33-34) were derived from Cancer Registry Annual Report (CRAR). The CRAR summarized the incidence, mortality, and population data of malignant tumors in the 31 provinces covered by tumor registration, including the proportion of death incidence, the proportion of pathological diagnosis, the proportion of only medical death certificate, and other quality control indicators. We adopted the longterm carbon emissions (CE) data released by China Emission Accounts and Datasets (CEADs, https://www.ceads.net.cn/data/province/by_sectoral_accounting/), It brings together a panel of experts from the UK, the US, and

China to study emissions accounting methods and applications in China, and to provide accurate and up-to-date carbon emissions as well as socio-economic and trade data is the responsibility of the entire academic field. Policy stakeholders and the public data for control variables are from the China Statistical Yearbook, including GDP index, primary industry index, secondary industry index, and urbanization rate.

\subsection{Variable}

\subsubsection{Dependent Variable: incidence rate of Lung cancer}

We collected 30 provinces with gender-specific lung cancer incidence rates (LIR) and lung cumulative incidence rates (LCIR) from 2013 to 2015 (due to the lack of carbon emissions data in Tibet, it was not included in this study). The age-standardized incidence rate was adjusted by Segi's world standard population. Robustness was tested using the LCIR, which is an overall index of the incidence of a particular disease at a particular stage by age (year), the formula is CIR $=\left[\sum\right.$ (age-specific incidence ratexagespecific interval)] $\times 100 \%$. Our research calculated the CIR from 0 to 74 years old.

\subsubsection{Independent Variable: carbon emissions}

This study used annual CE data to analyze the spatial impact of CE on LIR. We selected the annual CE data from CEAD from 1997 to 2015. At the same time, due to the time lag effect of Ce exposure on LIR, we also used primary carbon emission lag $\left(\mathrm{Ce}\left({ }^{-1}\right)\right)$ as an independent variable to test whether the time lag effect exists. In addition, carbon emissions per capita (PCE) and carbon emissions per capita lagging one stage (PCE $\left({ }^{-1}\right)$ ) were used as surrogate variables for CE exposure to test the robustness of the results. 


\subsubsection{Control Variable}

We assumed that LIR is not only affected by CE risk exposure, but also by other economic indicators. gross domestic product index $\left(I_{G D P}\right)$, primary industry index $\left(I_{P I}\right)$, secondary industry index $\left(I_{S I}\right)$, and urbanization rate (UR) were included as economic indicators in this study. Simply, energy consumption as the main production input, has improved the national economy. However, economic growth might have an influence on human health, as it requires fossil fuel consumption, and economic growth might have a positive influence on health infrastructure(Chaabouni 2016; Renton 2012).

\subsection{Study design}

\subsubsection{Research hypothesis}

Based on the above mentions, we propose the following hypotheses:

\section{Hypothesis 1}

Carbon emissions increase air pollution and will lead to lung cancer.

\section{Hypothesis 2}

The occurrence rate of lung cancer in the region is not only affected by the carbon emissions of its own region, but also by the carbon emissions of neighboring regions.

\section{Hypothesis 3}

The impact of carbon emissions on lung cancer has a time lag effect, that is, the amount of carbon emissions lagging for a period of time has a positive impact on the occurrence of lung cancer in the current period.

\subsubsection{Spatial Econometric Model}

This study analyzed the effect of carbon exposure on the incidence of lung cancer in China by using spatial econometric model, and measured the direct effect, spatial spillover effect and total effcet. According to the above assumptions, we built the spatial autoregressive model (SAR), spatial error model (SEM), and spatial Durbin model (SDM). (Anselin 2012). The SAR model explains the lag term of spatial dependent variables, SEM model explains the spatial spillover effect of independent variables, and SDM model explains the lag term of spatial dependent variables and spatial spillover effect of independent variables. Based on this, the three spatial econometric models are constructed as follows:

SAR:

$$
\ln Y_{i t}=\alpha+\rho W Y_{i t}+\beta_{1} \ln C E_{i t}+\beta_{2} \ln C E_{(-1)_{i t}}+\beta_{3} \ln I_{G D P_{i t}}+\beta_{4} \ln I_{P I_{i t}}+\beta_{5} \ln I_{S I_{i t}}+\beta_{6} \ln U R_{i t}+\epsilon_{i t}
$$

SEM:

$$
\begin{gathered}
\ln Y_{i t}=\alpha+\rho W Y_{i t}+\beta_{1} \ln C E_{i t}+\beta_{2} \ln C E_{(-1)_{i t}}+\beta_{3} \ln I_{G D P_{i t}}+\beta_{4} \ln I_{P I_{i t}}+\beta_{5} \ln I_{S I_{i t}}+\beta_{6} \ln U R_{i t}+\mu_{i t} \\
\mu_{i t}=\lambda W u_{i t}+\epsilon_{i t}
\end{gathered}
$$

SDM:

$$
\ln Y_{i t}=\alpha+\rho W Y_{i t}+\beta_{1} \ln C E_{i t}+\beta_{2} \ln C E_{(-1)_{i t}}+\beta_{3} \ln I_{G D P_{i t}}+\beta_{4} \ln I_{P I_{i t}}+\beta_{5} \ln _{S I_{i t}}+\beta_{6} \ln U R_{i t}+\sigma W X_{k i t}+\epsilon_{i t}
$$

where $\mathrm{Y}$ is the dependent variable; $\mathrm{CE}$ and $\mathrm{CE}_{(-1)}$ are the core independent variable; $\mathrm{I}_{\mathrm{GDP}}, \mathrm{I}_{\mathrm{Pl}}, \mathrm{I}_{\mathrm{SI}}$, and $\mathrm{UR}$ are the control variables; $\mathrm{X}$ represents all the above core independent variables and control variables; $W$ is the spatial weighting matrix; $\varepsilon_{i t}$ and $\mu_{i t}$ are normally distributed random error vector; a denotes the intercepted item; $\beta$ Is the influence coefficient of the independent variable on dependent variable; $\rho$ denotes the spatial autoregressive coefficient; $\lambda$ denotes the spatial error coefficient; $\sigma$ denotes the space lag coefficient of the independent variables; i represents regions, and t represents year. The logarithm is to minimize heteroscedasticity. 


\subsubsection{Spatial Autocorrelation Test}

Global and Local spatial correlation indexes were measured by global Moran's index (Moran's I) and Local Moran's I, respectively (Luc 1995). Their calculation formulas were shown as follows:

$$
\begin{gathered}
I=\frac{n}{\Sigma_{i} \Sigma w_{i . j}} \times \frac{\Sigma_{i} \Sigma_{j} w_{i . j}\left(x_{i}+\bar{x}\right)\left(x_{j}+\bar{x}\right)}{\Sigma_{i}\left(x_{i}-\bar{x}\right)^{2}} \\
I_{i}=\frac{n^{2}}{\Sigma_{i} \Sigma_{j} w_{i, j}}+\frac{\left(x_{i}-\bar{x}\right) \Sigma_{j} w_{i . j}\left(x_{j}-\bar{x}\right)}{\Sigma_{j}\left(x_{j}-\bar{x}\right)^{2}}
\end{gathered}
$$

Where, $x_{i}$ and $x_{j}$ represent the observed values of the region I and region $j$ respectively; $N$ is the number of all regions; $W_{i j}$ is an element in the spatial weight matrix; It's the mean of the sample.

Moran' I have a value between -1 and 1 . If its value is greater than 0 , then positive spatial autocorrelation exists between variables. If its value is less than 0 , there is a negative spatial correlation between the variables. If its value is equal to 0 , then there is no spatial autocorrelation between variables.

The measurement of Moran's I need to define spatial weight. In this study, the spatial contiguity matrix (W1) (Feng 2019)was used to describe the relationship among different regions. Specifically defined as: if region $\mathrm{i}$ and region $\mathrm{j}$ have a common boundary, then $\mathrm{W}_{\mathrm{ij}}=1$; otherwise, then $\mathrm{W}_{\mathrm{ij}}=0$. It should be noted that as an island, Hainan does not share a common border with other provinces. However, considering that Hainan has the closest connection with Guangxi and Guangdong, it also has two neighboring provinces.

\subsubsection{Model Test}

A common task often undertaken by space practitioners is model selection. Following the strategy described in LeSage and Pace (LeSage 2009) and Elhorst (Elhorst 2010), researchers should start with SDM as a general specification and test alternatives.

Because the SDM may be easily derived starting from an SEM, one can easily show that if $\lambda=0$, the model is a SAR, while if $\lambda=$ $-\beta \rho$, the model is an SEM.

In this study, we tested the conditions given in Table 3 to select a spatial econometric model to refer to this study of Belotti et al. (Belotti 2017) for panel data.

The main reasons for using the SDM are as follows: (1) When the ordinary least square method is used for regression, the perturbation term has spatial correlation, which leads to errors in regression results. (2) When dealing with regional sample data, some explanatory variables whose covariance with the explanatory variables in the model is not zero are ignored. In fact, the SDM is a SAR model enhanced by adding spatial lag variables.

In Table 3, the test results are significant at the $1 \%$ level $(P<0.01)$, and we should reject these invalid assumptions, i.e., $\lambda=0$ and $\lambda=-\rho \beta$; Therefore, SDM can be selected to analyze the impact of carbon emission exposure on lung cancer incidence in China. In addition, the results of Hausman test $\left(X^{2}=11.00, P=0.0514<10 \%\right)$ indicate that fixed effects should be used in spatial econometric models. In short, the SDM model with a fixed effect should be selected for analysis in this study.

\section{Spatial Distribution And Spatial Autocorrelation Analysis}

\subsection{Spatial Distribution}

Figure 1 showed the spatial distribution of LIR (Fig. 1(a1, b1, c1)), and CE (Fig. 1(a2, b2, c2)) from 2013 to 2015 in China, respectively. The incidence rate of lung cancer increased from 2013 to 2015, mainly in northeast, eastern, and central regions. 
There was no significant spatial change in carbon emissions from 2013 to 2015.

\subsection{Spatial Autocorrelation Analysis}

Before using spatial econometric model for empirical test, the global Moran index method was first used to test the spatial autocorrelation between LIR and CE from 2013 to 2015. The global Moran's I value of LIR, CE, I I spatial contiguity matrix W1 from 2013 to 2015 were shown in Table 4.

The results showed that the global Moran's I of LIR was significantly positive at the $5 \%$ and $1 \%$ levels in 2014 and 2015 , respectively; the global Moran's I of CE was significantly positive at the $5 \%$ level in 2013. The results indicated that there was a positive spatial correlation between the LIR and CE in China from 2013 to 2015. It was further illustrated that not considering spatial heterogeneity in the study of LIR and CE might lead to bias and the rationality of choosing spatial econometric models in this study.

To analyze the local agglomeration characteristics of LIR and CE, Fig. 2 showed the local Moran's I scatter plots of LIR and CE in 30 provinces (cities) in China. In local Moran's I scatter plot, the first quadrant and the third quadrant indicate positive spatial correlation, indicating high-high $(\mathrm{H}-\mathrm{H})$ value clustering and low-low $(\mathrm{L}-\mathrm{L})$ value clustering, respectively. The second and the fourth quadrants indicate negative spatial correlation, indicating low-high $(\mathrm{L}-\mathrm{H})$ value clustering and high-low $(\mathrm{H}-\mathrm{L})$ value clustering, respectively. Figure 2 showed that about 2/3 regions are located in the first quadrant or the third quadrant, representing that there was a positive spatial correlation between LIR and CE in most regions. For the local Moran's I scatter plots of LIR in 2013, about one out of three regions located in the first quadrant or the third quadrant, such as Beijing, Shanghai, Guangdong, Tianjin, Zhejiang, etc., were mostly eastern coastal provinces (cities). In the scatter plots of CE in 2013, there were 16 regions located in the first or third quadrants, such as Shanxi, Zhejiang, Jiangsu, etc.

\section{Results}

\subsection{Impact of CE on LIR}

On the basis of the model test results, the SDM was selected for panel data analysis.. Therefore, this study selected the SDM model with the spatial fixed effects (SFE), time fixed effects (TFE), and spatial-time fixed effects (S-TFE) for empirical testing. The results showed that all these coefficients of UR are significantly positive at the $1 \%$ level, which indicated UR will increase the LIR from 2013 to 2015. In the TFE, the coefficients of CE were positive at the $10 \%$ significance level, which pointed out that CE exposure had a long-term impact on LIR from 2013 to 2015.

The partial coefficients analysis of the SDM model by partial differential methods. The direct influence coefficient, the indirect effect coefficient, and total effects of each variable were obtained. The results were shown in Table 6.

Table 6 indicated that the direct effect coefficient of CE and UR were 0.132 and 0.425 , respectively, both significant at a $1 \%$ level, it showed that CE and UR had an obvious positive effect on LIR. While the indirect effect coefficient of all the variables was not significant at a $10 \%$ level, which indicated that CE had not impact on the LIR of its surrounding areas. The total effect coefficient is 0.005 , which is significant at the level of $1 \%$, indicating that the change of the total effect coefficient in a certain region has an average impact on LIR in different regions.

\subsection{Robustness Tests}

This study took the total CE as the key independent variable to analyze the spatial effect of CE on LIR. To minimize the selection bias of the independent and dependent variables, we chose the per capita carbon emissions (PCE) as the substitution variable of CE for the robustness test, and the lung cancer cumulative incidence rate (LCIR) as the substitution variable of LIR for the robustness test. The results were presented in Table 7. Among them, the column (1), column (2) were the results of the impact of PCE and one stage lag of PCE (PCE $(-1)$ ) on LIR based on the spatial matrices W1. The column (3), column (4) are the results of the impact of CE and one stage lag of CE $\left(\mathrm{CE}_{(-1)}\right)$ on LCIR based on W1. 
The results showed that the direct coefficient and the spatial lag coefficient of PCE and PCE $(-1)$ were significantly positive at the $1 \%$ level. This suggested that the PCE in a particular region or the adjacent regions had a positive impact on LIR in the particular region, with spatial spillover effect and temporal lag effect. The direct coefficient and the spatial lag coefficient of CE $(-1)$ were significantly positive at the $10 \%$ level. The results were consistent with the above conclusions, showing that the results were stable and reliable. In other words, CE had a temporal lag effect on LIR.

\subsection{Pearson test}

The association between long-term exposure to CE and LIR was quantified with the Pearson test. The Pearson test is applicable to data with bivariate non-normal distribution or unclear distribution, or data with one of the variables non-normal distribution. The Pearson correlation coefficients between the LIR in 2015 and CE in 1997-2012 were calculated. The results showed that the r value was highest from 1997 to 2011, except for 1997 and 2012(Table 8).

Based on the above findings, we determined that the strongest linear effect on the LIR from 1998 to 2011 . To get a stable relationship between the LIR in 2015 and CE on a larger time scale, the Pearson correlation between the LIR in 2015 and CE in a 4year average of 1997-2000, 2001-2004, 2005-2008, and 2009-2012 were calculated. The results from Pearson test showed that CE in all periods presented the strongest association with the LIR in 2015 , and the $p$-value was increasing $(p<0.05$, Table 9). This implied that CE in the period had the greatest impact on the LIR in 2015 in China, and the lag period was about 17 years.

\section{Discussions}

The results showed that the direct effect coefficient of CE was 0.132 , which is significant at a $1 \%$ level, indicating that CE had an obvious positive effect on LIR. Our results are consistent with previous research. There was an increasing evidence that cardiopulmonary was affected by potential factors from burning sources of air pollution sources. Akbari et al. (Akbari 2019)came up with a mechanism about how fossil fuel emissions induce cancer. The results showed that ROS-induced mitochondrial damage (as the main power generators of human cells) can induce cancer via a reduction in cellular adenosine triphosphate, leading to genetic instability. Hosgood et al. (Hosgood 2010) pooled seven studies from North America, Europe, and Asia to test solid-fuel use and lung cancer risk and found an association between lung cancer and coal use in Asia. Shang et al. (Shang 2010) indicated that the increase in air pollution would increase the overall mortality rate of cardiovascular and cerebrovascular diseases. Both laboratory and epidemiological studies have strongly indicated that carbon emissions had a negative impact on the incidence rate of lung cancer.

In addition, the direct effect coefficient of UR was 0.425 , which is significant at the level of $1 \%$, which showed that UR had an obvious positive effect on LIR. With the economic development, China's urbanization and industrialization are accelerating (Wang 2015). In 2010, the urban population in China reached 670 million, accounting for nearly 50\% of the total population (China Statistics Press 2013). Industrialization and urbanization have brought about a large amount of consumption of fossil fuels, especially the consumption of coal, and the average energy consumed by urban residents is almost three times that of rural residents, which has brought serious climate challenges and air pollution to cities and their surrounding areas(Qi 2013). In addition, the large amount of energy consumption has led to increase combustion of fossil fuels, which is considered as the main source of urban air pollution(Wang 2016;Zhang 2016).

The results of Moran's I indicated that there was a positive spatial correlation between the LIR and CE in China from 2013 to 2015. Although the indirect influence coefficient of all the variables was not significant at the level of $10 \%$, which indicated that CE had no impact on the LIR of its surrounding areas. In total effect coefficient of CE was 0.005 and was significant at a $1 \%$ level, which pointed out that the average effect of a change in CE in a certain region is on LIR in all regions. Therefore, the research results indicated that there are geographical differences in carbon emissions but there is no spatial spillover effects. Geographical location is also a key factor that determine carbon emissions. In some northern cities, such as Tianjin, Jinan, Tangshan, and Taiyuan, carbon emissions were relatively high due to the large amount of coal production in the surrounding areas and the heating policy in the north (Wang 2019). In 2010, per capita carbon dioxide emissions in northern cities of China reached 10.2 tons, which was $54 \%$ higher than in southern cities of China, partly due to the use of fuels, for heating during the cold season, especially coal (Shen 2017). 
In the TFE, the coefficients of CE were positive at the $10 \%$ significance level, which pointed out that CE exposure had a long-term impact on LIR from 2013 to 2015. In addition, the Pearson test implied that CE in the period has the greatest effect on Chinas LIR in 2015, and the lag period was about 17 years. Lung cancer was the result of the long-term exposure to environmental factors. Qu et al. analyzed the short-term, and long-term relationship between energy consumption, environmental pollution and public health in China from 1985 to 2014, and found that the proportion of coal consumption, smoke and dust emissions, and other effects on cardiovascular and respiratory diseases are significantly positively correlated in the short and long term (Qu 2017). This suggested that a long-term effort was needed to reduce the impact of carbon emissions on lung cancer rates.

Since 2013, China has drawn on the advanced experience of carbon emission control in the United States, Europe, and other countries, and selected seven provinces and cities, including Beijing, Tianjin, Shanghai, Chongqing, Shenzhen, Hubei, and Guangzhou (2016, and Fujian was added in 2015) to carry out pilot projects and implement a series of carbon emission reduction measures. Currently, 31 provinces (autonomous regions and municipalities directly under the central government) in China have adopted strict carbon emission regulations and other measures(Yongbin 2008). Therefore, adopting policies to reducing carbon emissions will have a positive impact on health.

\section{Abbreviations}

CE carbon emission

LIR lung cancer incidence rate

LCIR lung cancer cumulative incidence rate

$\mathrm{CO}_{2}$ carbon dioxide

CO carbon monoxide

GBD Global Burden of Disease

CRAR Cancer Registry Annual Report

CEADs China Emission Accounts and Datasets

PCE per capita carbon emissions

$I_{G D P}$ Indices of gross domestic product

$I_{P I}$ index of the primary industry

$\mathrm{I}_{\mathrm{SI}}$ index of the secondary industry

UR urbanization rate

SAR spatial autoregression model

SEM spatial errors model

SDM spatial Durbin model

SFE spatial fixed effects

TFE time fixed effects

S-TFE spatial-time fixed effects

\section{Declarations}




\section{- Ethical Approval}

Not applicable

\section{- Consent to Participate}

Yes, all of the authors Consent to Participate

\section{- Consent to Publish}

Yes, all of the authors consent to publish

\section{- Author contribution:}

The authors Baohua Wang and Shaoxia Dong designed the study, and both of them were the roles of writing-review \& editing. Fengdie He finished the formal analysis and methodology, such as the spatial autoregression model (SAR), spatial errors model (SEM) and spatial Durbin model (SDM), and the spatial autocorrelation test (Moran'l), robustness test; Yongqing Lin had a contribution to conceptualization of each variances in this paper, such as control variable of indices of gross domestic product, index of the primary industry, index of the secondary industry urbanization rate; and she also collected of all data.

All authors read and revised the manuscript for important intellectual content and approved the final manuscript.

\section{- Role of funding source:}

This research did not receive any specific grant from funding agencies in the public, commercial, or not-for-profit sectors.

\section{- Declaration of interests:}

The authors declare that they have no known competing financial interests or personal relationships that could have appeared to influence the work reported in this paper.

\section{- Availability of data and materials}

The datasets used and/or analysed during the current study are available from the corresponding author on reasonable request.

\section{- Acknowledgement:}

None

\section{References}

1. Akbari, H.; Taghizadeh-Hesary, F.; Heike, Y.; Bahadori, M. Cell Energy: A New Hypothesis in Decoding Cancer Evolution[J]. Arch. Iran. Med. AIM 2019; 22:733-735.

2. Anselin, L.; Arribas, B.D. Spatial Fixed Effects and Spatial Dependence in A Single Cross-Section[J]. Pap. Reg. Sci. 2013, 37, 17-23. https://doi.org/10.1111/j.1435-5957.2012.00480.

3. Belotti, F.; Hughes, G.; Mortari, A.P. Spatial Panel-Data Models Using Stata[J]. Stata J. 2017; 17:139-180. https://doi.org/10.1177/1536867x1701700109.

4. Chaabouni, S.; Zghidi, N.; Ben Mbarek, M. On the causal dynamics between CO2 emissions, health expenditures and economic growth[J]. Sustain. Cities Soc 2016; 22:184-191. https://doi.org/10.1016/j.scs.2016.02.001.

5. Collaboration G C K D, Tran K, Yamada T. Global, regional, and national burden of chronic kidney disease, 1990-2017: a systematic analysis for the Global Burden of Disease Study 2017[J]. Lancet 2020; 395(10225):709-733. https://doi.org/10.1016/j.eclinm.2020.100712.

6. Edenhofer, O. et al. IPCC Climate Change 2014: Mitigation of Climate Change[M]. Cambridge Univ. Press, 2014. Doi:10.1787/79c0724f-fr. 
7. Elhorst, P., G. Piras, and G. Arbia. Growth and convergence in a multiregional model with space-time dynamics[J]. Geogr Anal 2010; 42: 338-355. https://doi.org/10.1111/j.1538-4632.2010.00796.

8. Feng, Y.; Cheng, J.H.; Shen, J. Spatial Effects of Air Pollution on Public Health in China[J]. Environ. Resour. Econ. 2019; 73:229-250. https://doi.org/10.1007/s10640-018-0258-4.

9. Ghanem S K. The relationship between population and the environment and its impact on sustainable development in Egypt using a multi-equation model[J]. Environ, Dev and Sustain 2018; 20(1):305-342. https://doi.org/10.1007/s10668-016-9882-8.

10. Hosgood HD, Boffetta P, Greenland S, Lee YC, McLaughlin J, et al. In-home coal and wood use and lung cancer risk: a pooled analysis of the International Lung Cancer Consortium[J]. Environ Health Perspect 2010; 118(12):1743-7. https://doi.org/10.1289/ehp.1002217.

11. Joellen Lewtas. Air pollution combustion emissions: Characterization of causative agents and mechanisms associated with cancer, reproductive, and cardiovascular effects[J]. Mutat Res 2007; 636:95-133. https://doi.org/10.1016/j.mrrev.2007.08.003.

12. LeSage, J., and R. K. Pace. Introduction to Spatial Econometrics[J]. Boca Raton, FL: Chapman \& Hall/CRC; 2009. https://doi.org/10.1201/9781420064254-13.

13. Lin C, Lin R, Chen T, et al. A global perspective on coal-fired power plants and burden of lung cancer[J]. Environ Health 2019; 18(1). https://doi.org/10.1136/oemed-2017-104636.43.

14. Luc Anselin. Geographical Analysis[M]. Ohio State University Press 1995; Vol. 27, No.2.

15. National Bureau of Statistics of the People's Republic of China China Statistical Yearbook 2012 (China Statistics Press, 2013).

16. Qi, Y., Wu, T., He, J. \& King, D. A. China's carbon conundrum[J]. Nat. Geosci 2013; 6:507-509. https://doi.org/10.1038/ngeo1870.

17. Qu WH, Xu L, Qu GH, Yan ZJ, Wang JX. The impact of energy consumption on environment and public health in China[J]. Nat Hazards 2017; 87:675-697. https://doi.org/10.1007/s11069-017-2787-5.

18. Rafindadi, A.A.; Yusof, Z.; Zaman, K.H.; Kyophilavong, P.H.; Akhmat, G. The relationship between air pollution, fossil fuel energy consumption, and water resources in the panel of selected Asia-Pacific countries. Environ. Sci. Pollut. Res. 2014; 21: 1139511400. https://doi.org/10.1007/s11356-014-3095-1.

19. Renton, A.; Lintott, W.J. Economic growth and decline in mortality in developing countries: An analysis of the World Bank development datasets[J]. PH 2012; 126:551-560. https://doi.org/10.1016/j.puhe.2012.03.011.

20. Shang Y, Sun Z, Cao J, Wang X, Zhong L, et al. Systematic review of Chinese studies of short-term exposure to air pollution and daily mortality[J]. Environ Int 2013; 54:100-111. https://doi.org/10.1016/j.envint.2013.01.010.

21. Shen, H. et al. Urbanization-induced population migration has reduced ambient PM2.5 concentrations in China[J]. Sci. Adv 2017; 3: e1700300. https://doi.org/10.1126/sciadv.1700300.

22. Shihong Y, Yaru W, Jianpei W, Jun Chen. Relationships between lung cancer incidences and air pollutants. Technol Health Care[J]. Technol Health Care 2017; 25(S1):411-422. https://doi.org/10.3233/thc-171344.

23. Song Y. 2015 China Cancer Registry Annual Report[J]. Chinese Med Inf Guide 2018; 33(7):6.

24. Wang HK, Lu X, Deng Y, Sun YG, et al. China's CO2 peak before 2030 implied from characteristics and growth of cities[J]. Nat Sustain 2019; 2:748-754. https://doi.org/10.1038/s41893-019-0339-6.

25. Wang $K$, Zhu B, Wang P, Wei YM. Examining the links among economic growth, energy consumption, and $\mathrm{CO} 2$ emission with linear and nonlinear causality tests[J]. Nat Hazards 2016; 81:1-13. https://doi.org/10.1007/s11069-015-2124-9.

26. Wang, H., Zhang, Y., Lu, X., Nielsen, C. P. \& Bi, J. Understanding China's carbon dioxide emissions from both production and consumption perspectives[J]. Renew. Sustain. Energy Rev 2015; 52:189-200. https://doi.org/10.1016/j.rser.2015.07.089

27. Yongbin W Z Z. Study on the Status of Carbon Emission in Provincial Scale of China and Countermeasures for Reducing its Emission[J]. Bulle of the Chinese Acade of Sci 2008; 23(02):109-115. https://doi.10.16418/j.issn.1000-3045.2008.02.004.

28. Zhang YJ, Hao JF. The evaluation of environmental capacity: evidence in Hunan province of China[J]. Ecol Ind 2016; 60:514523. https://doi.org/10.1016/j.ecolind.2015.07.028/.

\section{Tables}

Page $10 / 17$ 
Table 1. Description of the variable.

\begin{tabular}{|c|c|c|c|}
\hline Type & Variable & Symbol & Definition \\
\hline \multirow{2}{*}{$\begin{array}{l}\text { Dependent } \\
\text { variable }\end{array}$} & Lung cancer incidence rate & LIR & $\begin{array}{l}\text { The lung cancer incidence rate in the form of the natural } \\
\text { logarithm }\end{array}$ \\
\hline & $\begin{array}{l}\text { Lung cancer cumulative incidence } \\
\text { rate }\end{array}$ & LCIR & $\begin{array}{l}\text { The lung cancer cumulative incidence rate in the form of } \\
\text { the natural logarithm }\end{array}$ \\
\hline \multirow{6}{*}{$\begin{array}{l}\text { Independent } \\
\text { variable }\end{array}$} & Carbon emissions & CE & $\begin{array}{l}\text { The annual carbon emissions in the form of the natural } \\
\text { logarithm }\end{array}$ \\
\hline & $\begin{array}{l}\text { Carbon emissions lag by one } \\
\text { stage }\end{array}$ & $\mathrm{CE}_{(-1)}$ & $\begin{array}{l}\text { The values of the last year's annual carbon emissions in } \\
\text { the form of the }\end{array}$ \\
\hline & & & natural logarithm \\
\hline & Per capita carbon emissions & PCE & $\begin{array}{l}\text { The per capita carbon emissions in the form of the natura } \\
\text { logarithm }\end{array}$ \\
\hline & $\begin{array}{l}\text { Per capita carbon emissions lag } \\
\text { by one stage }\end{array}$ & $\mathrm{PCE}_{(-1)}$ & $\begin{array}{l}\text { The values of the last year's per capita carbon emissions } \\
\text { in the form of the }\end{array}$ \\
\hline & & & natural logarithm \\
\hline \multirow{4}{*}{$\begin{array}{l}\text { Control } \\
\text { variable }\end{array}$} & Indices of Gross Domestic Product & $\mathrm{I}_{\mathrm{GDP}}$ & $\begin{array}{l}\text { The indices of gross domestic product in the form of the } \\
\text { natural logarithm }\end{array}$ \\
\hline & Index of the primary industry & $I_{P I}$ & $\begin{array}{l}\text { The index of the primary industry in the form of the } \\
\text { natural logarithm }\end{array}$ \\
\hline & Index of the secondary industry & $\mathrm{I}_{\mathrm{SI}}$ & $\begin{array}{l}\text { The index of the secondary industry in the form of the } \\
\text { natural logarithm }\end{array}$ \\
\hline & Urbanization rate & UR & $\begin{array}{l}\text { The index of the urbanization rate in the form of the } \\
\text { natural logarithm }\end{array}$ \\
\hline
\end{tabular}

Table 2. Descriptive statistics.

\begin{tabular}{|llllll|}
\hline Variable & Obs & Mean & S.D. & Min & Max \\
\hline LIR & 90 & 32.075 & 6.382 & 19.06 & 45.2 \\
\hline LCIR & 90 & 3.839 & 0.768 & 2.25 & 5.41 \\
\hline CE & 90 & 319.741 & 197.499 & 39.5 & 824.4 \\
\hline CE $_{(-1)}$ & 90 & 318.878 & 197.133 & 39.5 & 790.4 \\
\hline PCE & 90 & 0.888 & 0.094 & 0.04 & 0.85 \\
\hline PCE $(-1)$ & 90 & 0.080 & 0.047 & 0.04 & 0.23 \\
\hline I $_{\text {GP }}$ & 90 & 108.710 & 1.751 & 103 & 112.5 \\
\hline IPI & 90 & 103.743 & 2.890 & 86.39 & 106.9 \\
\hline ISI & 90 & 108.717 & 3.083 & 98.8 & 114.1 \\
\hline UR & 90 & 56.542 & 12.352 & 37.83 & 89.6 \\
\hline
\end{tabular}

Table 3. The selection results of spatial autoregression model (SAR), spatial errors model (SEM), and spatial Durbin model (SDM). 


\begin{tabular}{|lllll|}
\hline Name & Model & Selection Criteria & Chi-Square Value & $p$-Value \\
\hline SAR & $y=\rho W y+X \beta+\varepsilon$ & $\lambda=0$ & 17.44 & 0.0037 \\
\hline SEM & $y=X \beta+u, u=\lambda W u+\varepsilon$ & $\lambda=-\rho \beta$ & 26.43 & 0.0001 \\
\hline SDM & $y=\rho W y+X \beta+\lambda W X+\varepsilon$ & $\lambda 0 \& \lambda-\rho \beta$ & & \\
\hline
\end{tabular}

Hausman test: The Chi-square value is 11.00 , and the $p$-value is 0.0514 .

Table 4. Global Moran's I values of LIR, CE, I $I_{G D P}, I_{P \mid}, I_{S I}$, and UR (2013-2015).

\begin{tabular}{|c|c|c|c|c|c|c|c|c|c|c|c|c|}
\hline \multirow[t]{2}{*}{ Year } & \multirow[t]{2}{*}{ LIR } & \multicolumn{3}{|c|}{ CE } & \multirow[t]{2}{*}{$\mathrm{I}_{\mathrm{GDP}}$} & \multicolumn{3}{|c|}{$I_{P I}$} & \multirow[t]{2}{*}{$\mathrm{I}_{\mathrm{SI}}$} & \multicolumn{3}{|c|}{ UR } \\
\hline & & $p$ & & $p$ & & $p$ & & $p$ & & $p$ & & $p$ \\
\hline 2013 & 0.018 & 0.151 & 0.032 & $0.095^{\star}$ & 0.101 & $0.004^{\star \star \star}$ & 0.019 & 0.125 & 0.033 & $0.091^{*}$ & -0.023 & 0.411 \\
\hline 2014 & 0.037 & 0.020 ** & -0.055 & 0.278 & 0.026 & 0.040 ** & -0.024 & 0.380 & 0.059 & $0.004^{\star * *}$ & 0.015 & $0.071^{*}$ \\
\hline 2015 & 0.080 & $0.001^{* * *}$ & -0.070 & 0.149 & 0.015 & $0.068^{*}$ & -0.045 & 0.355 & 0.037 & $0.018^{\star \star}$ & 0.014 & $0.078 *$ \\
\hline
\end{tabular}

Note: $* * \star, * *$, and * denote significance at the $1 \%, 5 \%$, and $10 \%$ levels, respectively.

Table 5. Estimation results of the CE exposure on LIR. 


\begin{tabular}{|c|c|c|c|}
\hline Variable & SFE & TFE & S-TFE \\
\hline \multirow[t]{2}{*}{ InCE } & \multirow{2}{*}{$\begin{array}{l}0.210 \\
(1.26)\end{array}$} & $0.131^{\star \star \star}$ & 0.086 \\
\hline & & $₫ 4.24 \rrbracket$ & $\triangle 0.52 \rrbracket$ \\
\hline \multirow[t]{2}{*}{$\left.\operatorname{ln|}\right|_{G D P}$} & -1.760 & -1.455 & -3.510 \\
\hline & $(-0.91)$ & Q-0.42】 & $ه-1.58 \rrbracket$ \\
\hline \multirow{2}{*}{$|n|_{P I}$} & -0.585 & -0.367 & -0.469 \\
\hline & $(-1.17)$ & Q-0.41区 & $\bigotimes-0.96 \rrbracket$ \\
\hline \multirow[t]{2}{*}{$\operatorname{lnl}_{S I}$} & 1.226 & 1.171 & $2.606^{\star \star}$ \\
\hline & $(1.03)$ & $\triangle 0.54 \rrbracket$ & $\triangle 2.03 \rrbracket$ \\
\hline \multirow[t]{2}{*}{ InUR } & $-2.466^{\star \star \star}$ & $0.418^{\star \star \star}$ & $-3.175^{\star \star \star}$ \\
\hline & $(-3.46)$ & ه3.72】 & $\rrbracket-4.32 \rrbracket$ \\
\hline \multirow[t]{2}{*}{$W * \ln C E$} & -0.138 & 0.048 & -0.375 \\
\hline & $(-0.23)$ & $\triangle 0.60 \rrbracket$ & $\rrbracket-0.63 \rrbracket$ \\
\hline \multirow[t]{2}{*}{$\mathrm{W} * \mid \mathrm{nl}_{\mathrm{GDP}}$} & -3.710 & -4.027 & -3.767 \\
\hline & $(-1.06)$ & $\rrbracket-0.44 \rrbracket$ & $\rrbracket-0.60 \rrbracket$ \\
\hline \multirow[t]{2}{*}{$\mathrm{W}^{*}|\mathrm{n}|_{\mathrm{PI}}$} & -0.316 & -1.175 & 2.758 \\
\hline & $(-0.19)$ & 邓-0.31】 & $\otimes 1.37 \rrbracket$ \\
\hline \multirow[t]{2}{*}{$\left.\mathrm{W} * \mathbf{n}\right|_{\mathrm{SI}}$} & 1.183 & 4.109 & 3.778 \\
\hline & $(0.55)$ & $\triangle 0.79 \rrbracket$ & $\triangle 1.58 \rrbracket$ \\
\hline \multirow[t]{2}{*}{$W * \ln U R$} & 1.326 & 0.696 & -7.460 ** \\
\hline & $(0.86)$ & $\triangle 1.05 \rrbracket$ & $\rrbracket-2.11 \rrbracket$ \\
\hline \multirow[t]{3}{*}{$\mathrm{R}^{2}$} & 0.053 & 0.401 & 0.118 \\
\hline & 0.338 & -0.054 & 0.283 \\
\hline & $(1.55)$ & $\rrbracket-0.18 \rrbracket$ & $\nabla 1.28 \rrbracket$ \\
\hline \multirow[t]{2}{*}{ sigma2_e } & $0.004^{\star \star \star}$ & $0.026 * \star \star *$ & $0.003^{\star \star *}$ \\
\hline & $(6.66)$ & \$6.71ه & $\triangle 6.65 \rrbracket$ \\
\hline $\mathbf{N}$ & 90 & 90 & 90 \\
\hline
\end{tabular}

Notes: $* * *, * *$, and * represent significance at the $1 \%, 5 \%$ and $10 \%$ levels, respectively; The numbers in brackets are t statistic values.

Table 6. The direct effects, the indirect effects and the total effects of SDM. 


\begin{tabular}{|c|c|c|c|c|}
\hline Type & Variable & Coefficient & t-Value & $p$-Value \\
\hline \multirow{5}{*}{ Direct effects } & InCE & 0.132 & 4.05 & 0.000 \\
\hline & $|n|_{G D P}$ & -1.447 & -0.43 & 0.669 \\
\hline & $|n|_{P I}$ & -0.259 & -0.30 & 0.762 \\
\hline & $|n|_{S I}$ & 1.145 & 0.54 & 0.586 \\
\hline & InUR & 0.425 & 3.64 & 0.000 \\
\hline \multirow{5}{*}{ Indirect effects } & InCE & 0.042 & 0.63 & 0.531 \\
\hline & $|n|_{G D P}$ & -3.184 & -0.32 & 0.751 \\
\hline & $|n|_{P I}$ & -0.809 & -0.20 & 0.844 \\
\hline & $|\ln |_{S I}$ & 3.866 & 0.70 & 0.486 \\
\hline & InUR & 0.765 & 0.89 & 0.372 \\
\hline \multirow{5}{*}{ Total effects } & InCE & 0.174 & 2.83 & 0.005 \\
\hline & $|n|_{G D P}$ & -4.631 & -0.42 & 0.674 \\
\hline & $|n|_{P I}$ & -1.068 & -0.24 & 0.809 \\
\hline & $|\ln |_{S I}$ & 5.011 & 0.80 & 0.424 \\
\hline & InUR & 1.190 & 1.36 & 0.173 \\
\hline
\end{tabular}

Table 7. Results of the robustness tests. 


\begin{tabular}{|c|c|c|c|c|}
\hline \multirow[t]{2}{*}{ Variable } & LIR & LIR & LCIR & LCIR \\
\hline & $(1)$ & (2) & (3) & (4) \\
\hline \multirow[t]{2}{*}{ CE } & & & 0.114 & \\
\hline & & & $(0.54)$ & \\
\hline \multirow[t]{2}{*}{$C E_{(-1)}$} & & & & $0.002^{*}$ \\
\hline & & & & $\otimes 1.82 \rrbracket$ \\
\hline \multirow[t]{2}{*}{ PCE } & $0.057^{* \star *}$ & & & \\
\hline & \3.55》 & & & \\
\hline \multirow[t]{2}{*}{$\operatorname{PCE}_{(-1)}$} & & $8.552^{\star \star}$ & & \\
\hline & & $(2.19)$ & & \\
\hline \multirow[t]{2}{*}{$\mathrm{I}_{\mathrm{GDP}}$} & -2.178 & -0.629 & -1.628 & 0.741 \\
\hline & $\rrbracket-0.69 \rrbracket$ & $(-0.16)$ & $(-0.49)$ & $₫ 0.18 \rrbracket$ \\
\hline \multirow[t]{2}{*}{$I_{P I}$} & -0.654 & -0.502 & -0.537 & -0.811 \\
\hline & $\rrbracket-0.76 \rrbracket$ & $(-0.76)$ & $(-0.63)$ & $\rrbracket-1.02 \rrbracket$ \\
\hline \multirow[t]{2}{*}{$I_{S I}$} & 2.340 & 2.643 & 1.727 & 0.760 \\
\hline & ه1.26】 & $(1.41)$ & $(0.96)$ & $\bowtie 0.48 \rrbracket$ \\
\hline \multirow[t]{2}{*}{ UR } & $-2.775^{\star \star}$ & $-5.669 * * *$ & $-2.898 * \star$ & $-4.268 * \star \star *$ \\
\hline & $\rrbracket-2.54 \rrbracket$ & $(-4.91)$ & $(-2.60)$ & Q-3.31区 \\
\hline \multirow[t]{2}{*}{$\mathrm{R}^{2}$} & $0 \bigotimes 149$ & 0.167 & 0.101 & 0.080 \\
\hline & 0.986 & 0.998 & 0.987 & 0.996 \\
\hline sigma2_e & 0.079 & 0.061 & 0.080 & 0.072 \\
\hline $\mathbf{N}$ & 90 & 90 & 90 & 90 \\
\hline
\end{tabular}

Notes: $* \star \star, * \star$, and * represent significance at the $1 \%, 5 \%$ and $10 \%$ level, respectively; The numbers in brackets are t statistic values.

Table 8. Association between CE and LIR in each year.

\begin{tabular}{|lllllllll|}
\hline Index & 1997 & 1998 & 1999 & 2000 & 2001 & 2002 & 2003 & 2004 \\
\hline D & 0.146 & 0.106 & 0.169 & 0.08 & 0.131 & 0.042 & 0.067 & 0.099 \\
\hline r & 0.459 & 0.488 & 0.529 & 0.55 & 0.556 & 0.489 & 0.406 & 0.435 \\
\hline -value & 0.110 & $0.006^{\star}$ & $0.003^{\star}$ & $0.002^{\star}$ & $0.001^{*}$ & $0.006^{*}$ & $0.026^{*}$ & $0.016^{*}$ \\
\hline D & 0.008 & 0.014 & 0.013 & 0.007 & 0.008 & 0.005 & 0.009 & 0.028 \\
\hline r & 0.389 & 0.387 & 0.422 & 0.421 & 0.37 & 0.389 & 0.372 & 0.341 \\
\hline$p$-value & $0.034^{\star}$ & $0.035^{\star}$ & $0.020^{\star}$ & $0.020^{\star}$ & $0.044^{*}$ & $0.034^{*}$ & $0.043^{*}$ & 0.066 \\
\hline
\end{tabular}

Note: D indicates normal test; $r$ indicates Pearson's correlation. * indicates $p<0.05$. 
Table 9. Association between CE and LIR in a 4-year.

\begin{tabular}{|lllll|}
\hline Index & $1997-2000$ & $2001-2004$ & $2005-2008$ & 2009-2012 \\
\hline r & 0.513 & 0.451 & 0.421 & 0.372 \\
\hline$p$-value & $0.004^{\star}$ & $0.012^{\star}$ & $0.021^{\star}$ & $0.043^{\star}$ \\
\hline
\end{tabular}

Note: $r$ indicates Pearson's correlation. * indicates $p<0.05$.

\section{Figures}

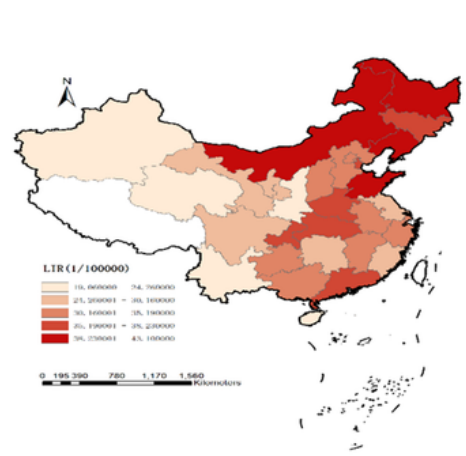

al. The spatial distribution of lung cancer incidence rate in 2013

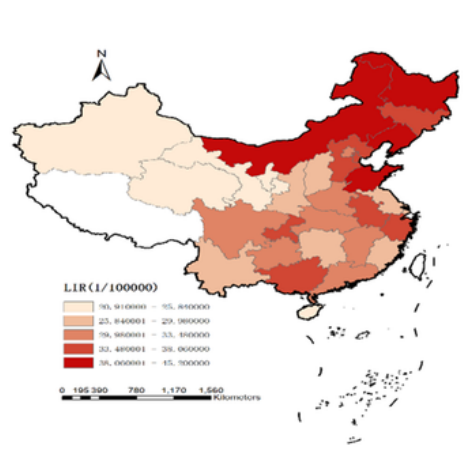

b1. The spatial distribution of lung cancer incidence rate in 2014

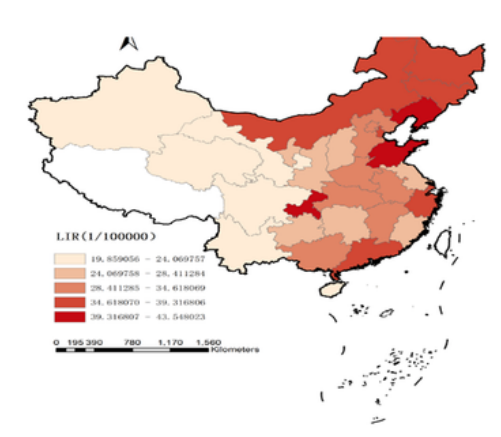

c1. The spatial distribution of lung cancer incidence rate in 2015

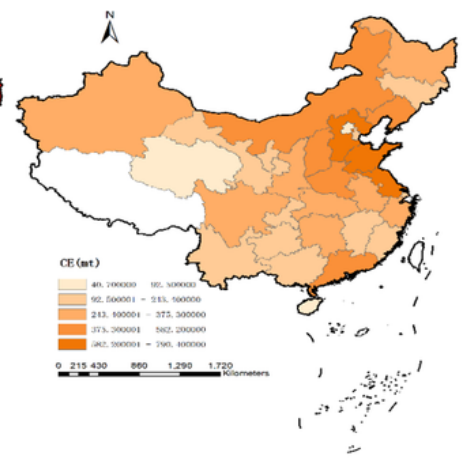

a2. The spatial distribution of carbon emissions in 2013

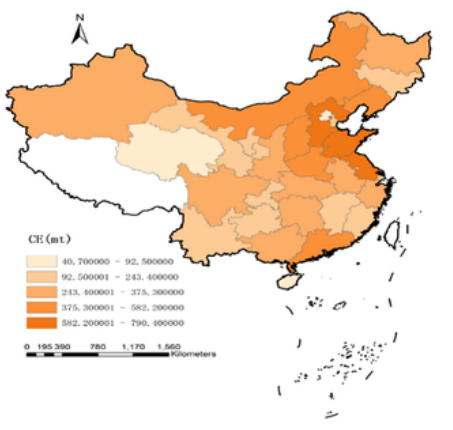

b2. The spatial distribution of carbon emissions in 2014

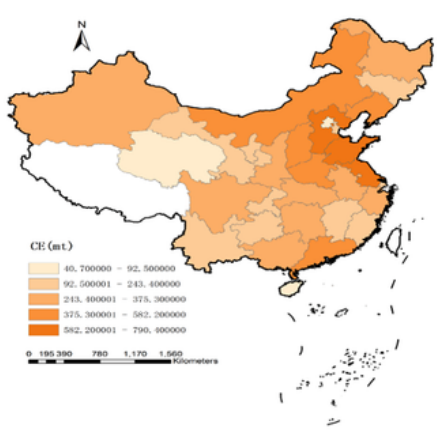

c2. The spatial distribution of carbon emissions in 2015

\section{Figure 1}

The spatial distribution of the core variables in 2013, 2014, and 2015. 

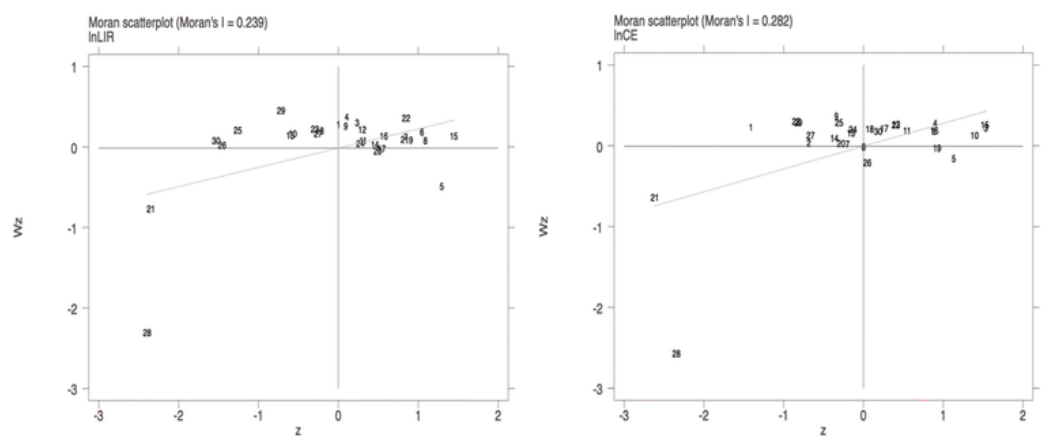

a1. Local Moran's I scatter plot of LIR in 2013

a2. Local Moran's I scatter plot of CE in 2013
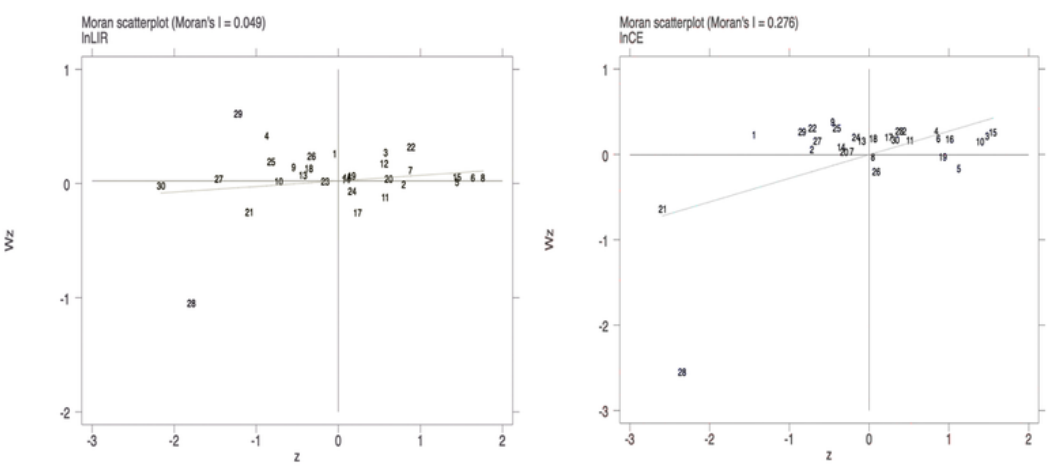

b1. Local Moran's I scatter plot of LIR in 2014

b2. Local Moran's I scatter plot of CE in 2014
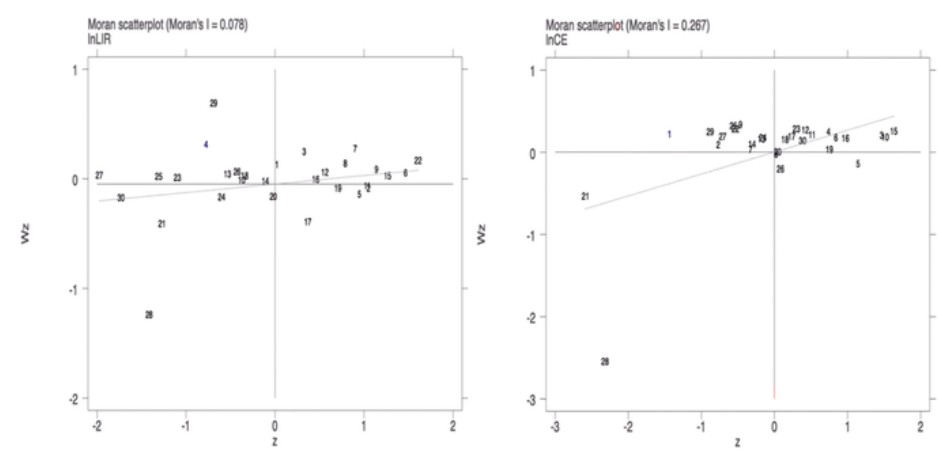

c1. Local Moran's I scatter plot of LIR in 2015

c2. Local Moran's I scatter plot of CE in 2015

\section{Figure 2}

Local Moran's I scatter plot in 2013, 2014 and 2015. Note: Numbers 1 to 30 represent Beijing, Tianjin, Hebei, Shanxi, Inner Mongolia, Liaoning, Jilin, Heilongjiang, Shanghai, Jiangsu, Zhejiang, Anhui, Fujian, Jiangxi, Shandong, Henan, Hubei, Hunan, Guangdong, Guangxi, Hainan, Chongqing, Sichuan, Guizhou, Yunnan, Shaanxi, Gansu, Qinghai, Ningxia and Xinjiang, respectively. 